\title{
Resource Integration as a Perspective on Value in Interaction Design
}

\author{
Tim Overkamp, Johan Blomkvist, Vanessa Rodrigues, Mattias Arvola, Stefan Holmlid \\ Linköping University \\ 58183 Linköping \\ firstname.lastname@liu.se
}

\begin{abstract}
Service-dominant logic (SDL) is a theoretical framework that has impacted the development of service design. Resource integration, a core concept in SDL, provides a distinctive perspective that changes the perception of value in situations of interaction. In this paper, we explore the implications of applying the resource integration view on interaction in the context of an illustrative design project. We argue that considering the resources of each actor in a design situation elevates the discussion towards a more strategic level of service and value creation. Through the example, we draw implications of utilising this perspective in specifying, positioning and shaping interactions in the system to provide value for different actors.
\end{abstract}

Interaction design, service design, resource integration, service-dominant logic, service logic.

\section{INTRODUCTION}

Interaction design can be characterised as a field of design with an emphasis on people's interactions with systems, as well as their experiences of those interactions. In this position paper, we suggest that resource integration is a useful perspective on value in interaction design. Resource integration is one of the core concepts in the service-dominant logic (SDL) theory. SDL, in turn, influences the theoretical development of service design. In showing how resource integration as a lens influences our understanding of a design case, we argue that SDL, and resource integration in particular, can also influence interaction design.

\section{RESOURCE INTEGRATION}

We start by introducing the concept of resource integration, and its role in the larger theory of service-dominant logic (SDL). SDL was introduced by Vargo and Lusch (2004) as an alternative to a Goods-Dominant Logic. In Goods-Dominant Logic, value is considered to be embedded in operand resources (goods) by means of production. This value becomes available to a customer upon exchange of such operand resources (with a 'd'). Rather than transferring the value of a product or service upon purchase, Vargo and Lusch (2011) suggested that value is co-created by multiple actors, through the exchange and integration of resources such as knowledge, skills, information, etc. (operant resources, with a ' $\mathrm{t}$ '). As a result, service provision (the exchange and integration of operant resources) replaces the exchange of goods as the basis of economic exchange. The term 'service' indicates a shift from conceptualising value creation in terms of operand resources to operant resources. SDL views service as the process of doing something for and with another party, and therefore inherently as a collaborative process (Vargo et al., 2010). Goods are still considered part of service provision, but primarily as distribution mechanisms for operant resources, rather than for their value as operand resources.

This service perspective is not limited to a dyadic situation with one provider and one customer. It rather considers value co-creation as something that takes place between multiple actors in a service system (Spohrer et al., 2007). These service systems are shaped by institutions and technology (Edvardsson et al., 2014; WetterEdman et al., 2014). The generic term actor can refer to people, such as customer or employee, but also to rules or government bodies indicating that they are distinctly constituted identities associated with different institutions (Vargo \& Lusch, 2011). An actor-to-actor orientation implies that value creation occurs in networks, and that there are mechanisms to facilitate and coordinate resource integration and service exchanges between actors (Vargo \& Lusch, 2016).

Value co-creation builds on the idea that actors produce, exchange, and integrate resources with other actors to realise outcomes that they cannot achieve alone. However, value co-creation is not guaranteed to take place, and it is even possible 
that the opposite occurs, i.e. value co-destruction (Echeverri \& Skålén, 2016). Whether or not value can be co-created depends on actors' access to resources through exchange. This is influenced by the social and cultural context (Chandler \& Vargo, 2011). For instance, knowing certain people allows you to, through their network, exchange resources that you may not have access to directly.

Furthermore, actors need to be able to integrate resources that are offered for exchange with their own resources. As a result, actors who provide resources for exchange never provide value by definition, but only potential value. This is also referred to as value propositions. For instance, a car manufacturer does not provide value by producing and selling cars, but only potential value of transport. Whether this value can be realised depends on whether the resource "car" can be integrated by other actors with their set of resources (e.g. having a driving license, access to roads, fuel, and repairs). In other words, realisation of value is in the eye of the beholder. Vargo and Lusch defined this as follows: "Value is always uniquely and phenomenologically determined by the beneficiary" (Vargo \& Lusch, 2008, p.7). This means that the person who engages in resource exchange with the purpose of value co-creation is the only one who can determine whether the intended outcome is actually achieved. From a service perspective, the object of design is thus not only the experience of using a product or service, but also-and perhaps more importantly-the preconditions that facilitate resource exchange and integration (Wetter-Edman et al., 2014).

Exchange and integration of resources does not require ownership over all the resources, merely access to them. Travellers can make use of trains and airplanes without owning them. Instead, they have access to some of the features of this mode of transportation by purchasing a ticket. Resources can also be accessed through lending or renting. In the example of the car as a resource, there would be no difference between whether the car is available through ownership or, for instance, a car sharing programme. Nonetheless, value is multifaceted and defined by the beneficiary, and there may be values of social significance that come with ownership (Arvola \& Holmlid, 2016).

According to SDL, whether or not value can be cocreated depends on how resources can be integrated, and on the context in which integration takes place. As a result, it is important to consider the context in which actors find themselves (Edvardsson, Tronvoll, \& Gruber, 2011). Resources offered for exchange should also fit the practice of the intended beneficiary of the resources (Grönroos \& Ravald, 2011).

Applying an SDL perspective to interaction design highlights that interactive systems are part of service systems. It emphasises the role of resources and their meaningful integration toward co-creation of value and achieving better outcomes for the multiple actors involved. SDL changes the object of design from the experiences of interacting with digital devices to the value that is co-created by the integration of resources that takes place during or because of such interactions. Thereby, SDL complements existing perspectives on interaction design and user experience (UX).

In short, SDL focuses on how various actors engage in exchange and integration of operant resources to the end of co-creating value. Whether or not resources can be integrated, and thus whether value can actually be co-created depends on contextual factors. A firm understanding of the practices of the actors that integrate resources is required to successfully design the prerequisites for value co-creation (i.e. value propositions).

\section{DESIGN EXAMPLE}

We now turn to a brief design case where SDL is applied. Two of the authors work with a manufacturer of trucks and buses. The aim of their project is to gain knowledge on software that can provide guidance for troubleshooting of trucks and buses. The software is intended to be used by multiple actors, such as the receptionist at a workshop, or mechanics and in different stages of the process illustrated in Figure 1.

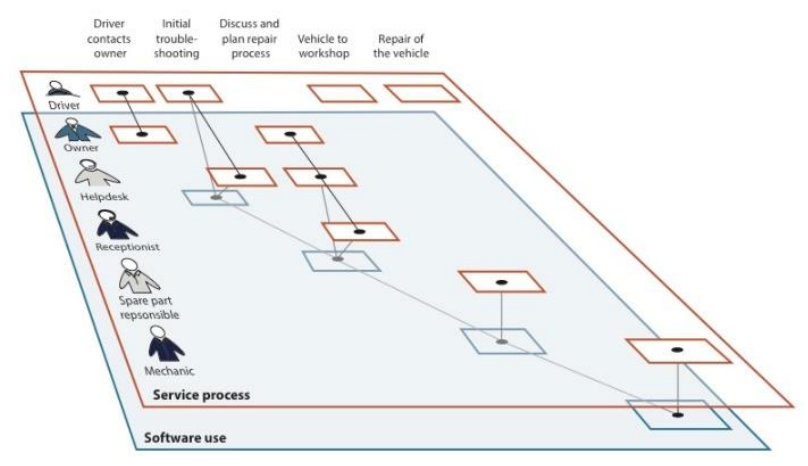

Figure 1: The envisioned service process (orange plane above) and the use of the software during this process (blue plane below), either to facilitate interactions between two or more human actors or in one-on-one interaction with one human actor (adapted from Overkamp \& Holmlid (2016)).

Based on information collected about a troubleshooting case, such as error codes produced by the on-board computer of the truck, the software will suggest next steps to help effectively, and yet inexpensively identify the root cause of the problem. Based on likely root causes, the software provides information about time and parts that are required for the repair. Another part is hardware and software 
for remote troubleshooting, before the vehicle has arrived at a workshop. Remote troubleshooting will be performed by a helpdesk operator. In addition to providing guidance during diagnosis, the software will have a history of what has happened previously in the process of troubleshooting and repair. When actors in the service process access the software, they can read what has been done and document their own actions for those who will work on the vehicle later on. This is indicated by the grey lines in the "software use" plane in Figure 1, that connect the boxes with the blue outline that show where in the process the software is used.

\section{APPLYING A RESOURCE INTEGRATION PERSPECTIVE}

When applying a resource integration perspective to this project, several aspects regarding the software are highlighted. Firstly, the functions of the software can be used as a resource in different ways by various actors in the service system for repairing trucks and buses. It can be used to gather information about a case: what has been done so far, what information has been collected. The different actors that access the software to gather this information differ in terms of the technical knowledge that they have about trucks and buses. For each actor to be able to integrate the information resources in the software with the knowledge resources that they already have, the information needs to be presented differently for each actor. Human actors also require additional software-related skills in order to successfully integrate the resources provided by the software with the other existing, accessible resources.

In addition, the functions of the software can be used as a resource in interactions between human actors. For instance, when a driver calls the helpdesk, the software is used to steer the remote troubleshooting and provide information to the driver about remote tests that are performed. In turn, drivers can be the eyes and ears for the helpdesk operator, providing knowledge that complements the resources the helpdesk has access to via the software. When the workshop and the logistic planner plan the repair, they use the software as a resource to determine the best course of action. They do this by integrating the information about repair times from the software with their own knowledge about other work scheduled at the workshop and planned deliveries, respectively.

A resource integration perspective highlights ways of value co-creation that become possible through the deployment of the software and hardware. It becomes possible to start troubleshooting earlier and provide all actors with information even before the truck is in the workshop. As a result, logistic planners get detailed information about the time needed for a repair beforehand, so that they have more time and margin to make changes to routes and planned deliveries where needed. This in turn allows them to provide their customers with more detailed information about possible delays earlier than what is currently possible.

For the workshop receptionist, having initial information about possible root causes, necessary parts, and repair time helps determine if and when they have time to repair the truck. In addition, since they have this information before the truck arrives, they can check whether they have the required parts in stock, and they can use the time until the truck arrives to acquire parts (e.g. from a neighbouring workshop).

Finally, drivers are expected to get more clarity on what the near future will look like after the remote troubleshooting, and they do not have to repeat their story about the experienced issue.

The resource integration perspective highlights how the software plays a role in facilitating (1) the creation of operant resources earlier in the process (compared to the present situation), and (2) the exchange and integration of these resources between actors in the service system. Due to the software, service actors who today become involved and receive operant resources during later stages in the process will have the opportunity to integrate these resources with their own skills and knowledge earlier, thus creating value both for themselves (e.g. better workshop management) and other actors (e.g. more detailed estimate of repair time for a driver).

Furthermore, the resource integration perspective makes it possible to determine what functions are needed on the level of the service system for troubleshooting and repairing trucks and buses. Consequently, it becomes possible to explore different ways of distributing these functions across different human actors and computer systems, to find alternatives that optimally facilitate the exchange and integration of resources between software, helpdesk, driver, logistics planner, receptionist, etc. For example, should the software only present information (e.g. error codes), so that human actors can integrate this information resource with their own resources (e.g. knowledge, experience) or should the software only present the most likely root cause based on information collected about the case? The next section discusses the implications of applying such a perspective in the broader context of interaction design.

\section{DISCUSSION}

Firstly, SDL considers actors in a service system. This includes not only those who directly interact with/through digital systems (direct users), but also 
those who do not necessarily use the digital system but are nonetheless affected by it (indirect users). In the case of the troubleshooting software, drivers and their logistic planners do not use the software themselves. Only the helpdesk, the mechanics and possibly the receptionists interact with the guided troubleshooting system. Yet, the information about the nature of the problem and the expected time and cost of the repair are resources that-if integrated with the resources of the driver and the logistics planner-allow additional value co-creation. Considering this situation to be about resource integration highlights the relations between actors and what different actors perceive as valuable.

Perhaps of more specific importance is the fact that contextualising the situation as resource integration means that design must focus on the prerequisites for resource integration, which in turn enables value co-creation. Service is then seen as co-created in service systems, rather than by using digital systems.

By highlighting the exchange and integration of resources, the design situation expands beyond users that interact with the digital systems and the user experience during those interactions. A resource integration perspective includes how interactions between users and the digital system relate to value co-creation of other actors in the service system, who do not interact with the system directly. We consider this expanded perspective to reside on a service system level. For successful interaction design as a part of a service system it thus becomes important that the digital system can be a resource, or provide resources, for such value co-creation. This leads to further design considerations. For instance, the software does not necessarily suggest the closest workshop, but the one that is conveniently located and has the parts that are needed in stock. This requires information (a resource) about the route of the truck or bus, and how urgent the problem is.

\subsection{Benefits for Interaction Design}

Since functions can be discussed on a service level, it becomes possible to explore and articulate how resources can be distributed among different human and non-human actors in the service system. From these different alternatives, the preferred option can be selected and used to inform development of the interactive system, and the integration of a particular interactive system solution with other actors or interactive systems in a service.

For instance, in the troubleshooting case, the software can be developed so that it uses information about error codes to present the most likely root cause and provide instructions for the most suited next step to rectify the cause of the problem and repairing the vehicle. In that case, mechanics would integrate the operant resources of the software with their physical skills in repairing the vehicle. In a way, they do what the software instructs them to do. Another option would be that the software uses the error codes to present several possible root causes and a shortlist of fitting actions or additional tests that can be performed in order to arrive at the actual root cause. In that case, the mechanics need to integrate this information with their existing knowledge about the workings of the truck or bus, about the preferences of the vehicle owner, and about previous cases, to determine what would be the best course of action. The resources provided by the software and the mechanic are different in both situations. Value co-creation requires that the resources are adapted so that they can be integrated. Either option has consequences for both the design of the digital system in regard to what resources it should produce for exchange and what knowledge and skills the mechanics need to possess to successfully integrate the resources.

We summarise the benefits of a resource integration perspective in interaction design below. Using resource integration as a perspective in interaction design:

- allows articulation of the role of the interactive system in the exchange and integration of operand and operant resources,

- identifies and explicates resources,

- abstracts interactions from those resources, thus making them available for design choices at the strategic, service system level.

\section{CONCLUSIONS}

We have introduced the concept of resource integration and, by pointing to a design case, we have illustrated how the concept influences the framing of the design situation and the corresponding design opportunities. From a resource integration perspective, actors exchange and intergrate resources to co-create value. The way this exchange occurs can be the object of design efforts and design alternatives concern not only how, but also in what medium interactions take place. Resource integration is best understood on the service level. Subsequently, this has implications for what interactions take place where in the system, and how they should be shaped to provide value for different actors. Finally, the notion of resource integration highlights that the resources provided by the digital system need to be shaped in such a way that actors who interact with and through the system are able integrate these resources with the resources that they already have access to in order to co-create value. 


\section{ACKNOWLEDGEMENTS}

Research funded by Strategic Vehicle Research and Innovation (FFI) of the Swedish Governmental Agency for Innovation Systems (Vinnova), project DiaGuide2 Dnr: 2014-03942

\section{REFERENCES}

Arvola, M., \& Holmlid, S. (2016). Service design ways to value-in-use. In Service Design Geographies. Proceedings of the ServDes.2016 conference (p. 530-536). 24-26 May, 2016, Copenhagen, Denmark.

Chandler, J. D., \& Vargo, S. L., (2011). Contextualization and value-in-context: How context frames exchange. Marketing Theory 11, 1, 35-49.

Echeverri, P., \& Skålén, Per. (2011). Co-creation and co-destruction: A practice-theory based study of interactive value formation. Marketing Theory 11, 3, 351-373.

Edvardsson, B., Kleinaltenkamp, M., Tronvoll, B., McHugh, P., \& Windahl, C. (2014). Institutional logics matter when coordinating resource integration. Marketing Theory 14, 3, 291-309.

Edvardsson, B., Tronvoll, B., \& Gruber T. (2011). Expanding understanding of service exchange and value co-creation: a social construction approach. Journal of the Academy of Marketing Science 39, 2, 327-339.

Grönroos, C, \& Ravald, A. A., (2011). Service as business logic: implications for value creation and marketing. Journal of Service Management 22, 1, 5-22.

Overkamp, T., \& Holmlid, S. (2016). MultiTouchpoint Design of Services for
Troubleshooting and Repairing Trucks and Buses. In: Experience Design for Multiple Customer Touchpoints, workshop in conjunction with NordiCHI'16, 23-27 October, 2016, Gothenburg, Sweden.

Spohrer, J., Maglio, P. P., Bailey, J., \& Gruhl, D. (2007). Steps toward a science of service systems. IEEE Computer Society 40, 1, 71-77.

Vargo, S. L., \& Lusch, R. F., Akaka, M. A. \& Yi He, Y. (2010). The service-dominant logic of marketing: a review and assessment. In Review of Marketing Research, Volume 6, Naresh K. Malhotra (ed.). Emerald Group Publishing Limited, 125-167.

Vargo, S. L. \& Lusch, R. F. (2004). Evolving to a new dominant logic for marketing. Journal of Marketing 68, 1, 1-17.

Vargo, S. L., \& Lusch, R. F. (2008). Servicedominant logic: continuing the evolution. Journal of the Academy of Marketing Science 36, 1, 110.

Vargo, S. L., \& Lusch, R. F. (2011). It's all B2B...and beyond: Toward a systems perspective of the market. Industrial Marketing Management 40, 2, 181-187.

Vargo, S. L., \& Lusch, R. F. (2016). Institutions and axioms: an extension and update of servicedominant logic. Journal of the Academy of Marketing Science 44, 1, 5-23.

Wetter-Edman, K., Sangiorgi, D., Edvardsson, B., Holmlid, S., Grönroos, C., \& Mattelmäki, T. (2014). Design for value co-creation: Exploring synergies between design for service and service logic. Service Science 6, 2, 106-121. 